\title{
Некоторые особенности потребления СМИ представителями отечественного делового сообщества
}

Эмма Терченко

Статья представляет собой первое исследование, направленное исключительно на изучение потребления СМИ представителями российского делового сообщества (на примере финансовой сферы). В ней выявлены и проанализированы основные предпочтения отечественных бизнесменов относительно типов и брендов СМИ, а также частота и способы взаимодействия с ними. Сделан вывод о том, что медиапотребление бизнесменов достаточно интенсивно, однако при этом отличается значительной консервативностью и однообразием.

Ключевые слова: медиапотребление, бизнес, финансы

\section{Введение}

Вопрос об особенностях потребления СМИ той или иной категории граждан относится к пласту исследований аудитории медиа. Массовая аудитория (или аудитория массовой коммуникации) представляет собой численно большие гетерогенные группы рассредоточенных в пространстве индивидов, объединенных лишь тем, что они получают общее медиасообщение (Полуэхтова, 2012: 136). Такие группы объединены общим интересом в тот или иной момент времени, общим действием в данный период, воздействие на них оказывается ради одной цели, что, по мнению И.А. Полуэхтовой, «позволяет рассматривать их как социальную общность».

У такой аудитории в наши дни присутствует ряд особенностей, что не может не отразиться на практиках медиапотребления. С этим приходится считаться и СМИ. В первую очередь среди таких особенностей - ограниченный ресурс внимания человека, который уже не в состоянии воспринимать все медиасообщения в цифровой среде. А.И. Черных (2008) отмечает в связи с этим понятие «шума» - помех для восприятия нужной информации, что особенно характерно для СМИ в эпоху Интернета. Отличить шум от сообщения может только получатель, решающий, какая 
информация для него важна, констатирует А.И. Черных (2008: 59). Время, отводимое под медиапотребление, теперь увеличилось в среднем на полчаса в день за счет того, что мы общаемся в социальных сетях на работе, читаем новости с наших мобильных устройств и просматриваем информационные сайты с офисных компьютеров (Качкаева, Шомова (ред.), 2017: 278). Зритель становится пользователем, он больше ориентируется в информации и все больше знает, чего он точно хочет, отмечает А.Г. Качкаева (2017).

Медиапотребление с мобильных устройств заняло такие слоты времени, как поездка на работу и с работы, обеденный перерыв, что сгладило традиционные еще в «нулевые» утренние и вечерние пики потребления, утверждает А.А. Амзин (2016: 92). «Это позволяет медиа завоевать с помощью “журналистики взгляда" новые слоты времени, например, совещания (нет времени на реакцию, есть время на потребление); нахождение за рулем (есть аудиоканал потребления, законодательно запрещено активное потребление информации); ситуации, связанные с неожиданно возникшими запросами (так называемые “микромоменты“)», - делает вывод Амзин (2016: 93).

Исследователи выделяют 16 вариантов практик потребления текстов СМИ в Интернете: чтение (reading), смотрение (watching), просмотр (viewing), слушание (listening), проверка (checking), перекус (snacking), беглое просматривание (scanning), мониторинг (monitoring), поиск (searching), нажатие (clicking), ссылка (linking), распространение (sharing), предпочтение (liking), рекомендация (recommending), комментирование (commenting), голосование (voting) (Meijer, Kormelink, 2014: 14). Исходя из этих данных, можно сделать вывод о том, что практики медиапотребления различаются по степени вовлеченности (взаимодействие активное или однообразное, например, скрол- линг), наличию обратной связи, глубине проникновения сообщения в сознание и т.п. Н.Г. Лосева (2016: 50) определяет три основных сценария обращения аудитории к новостям в СМИ: выраженная интенция, ситуативная интенция (отбор отдельных интересных тем или чтение новостей только в ситуации breaking news), пассивная или импульсивная интенция.

Исследователи отметили 30 причин, по которым читатели либо кликают, либо нет на новость в Интернете (Kormelink, Meijer, 2018: 28). Они делят их на три уровня: умственный, эмоциональный и практический. При этом можно допустить, что умственные соображения не ограничиваются целенаправленным поиском нужной информации, но включают в себя, например, узнавание (или не узнавание) новости («тревожный звоночек», «разрыв шаблона»), а также то, как представлена новость: разрозненные факты, мнение, новая перспектива. Аналогичным образом эмоциональные соображения выходят за рамки развлечения или поиска позитивных новостей и включают в себя подпитку негативных (например, разочарование) или смешанных чувств (радостное раздражение) (Kormelink, Meijer, 2018: 32).

На этом фоне ученые выделяют так называемые репертуары медиапотребления. Больше всего времени люди тратят на «домашние медиа», потребляемые с помощью стационарных средств (телевизор, компьютер). Телевидение остается самым популярным медиа для домашнего потребления не только у людей старшего возраста или граждан с низким уровнем образования (Harsh, Webster, Malthouse, Ksaizek, 2012: 113). Впрочем, более образованные и обеспеченные люди предпочитают онлайн-медиа, причем все чаще потребляют их на работе, что подразумевает, как правило, непредсказуемость и ситуативность выбора того или иного сообщения (Harsh, Webster, Malthouse, Ksaizek, 2012: 116). 
В этих условиях само содержание сообщений медиа отходит на второй план: чтобы читатель прочел текст, он совсем не обязательно должен быть хорошо написан или содержать в себе ценную информацию (Verhoeven, von Rimscha, Krebs, Siegert et al., 2017; Nelson, Webster, 2017; Boczkowski, Mitchelstein, 2010). Процесс обработки информации для новостей обычно стандартизирован, и, кроме того, контент по большей части предопределен его объективной важностью для всех или субъективными запросами аудитории того или иного СМИ. Исследователи давно пришли к выводу о существовании разрыва между представлениями аудитории об «интересности» новостей и мнением редакторов на этот счет (Fishman, 1980; Gans, 2004; MacGregor, 2007). Некоторые ученые говорят о том, что разрыв уменьшается или нивелируется только в том случае, если происходят события крайней важности для большого количества людей - например, финал президентской гонки привлекает внимание даже далеких от политики людей (Boczkowski, Mitchelstein, 2010: 27).

Исследователи выделяют также следующие наиболее важные «критерии успеха» СМИ в новой среде: грамотное распространение (в том числе на разных платформах), понимание рынка и нахождение своей ниши, дизайн, человеческие ресурсы (Verhoeven, von Rimscha, Krebs, Siegert et al., 2017: 26).

Если говорить об актуальном состоянии медиапотребления в России, то средний уровень медиаохвата россиян в 2019 г., как следует из исследования консалтинговой компании Deloitte «Медиапотребление в России - 2019», составил 52\%, лишь на один процентный пункт сократившись по сравнению с предыдущим годом². Несмотря на то что печатные СМИ более популярны среди москвичей, за год количество читающих прессу в столице сократи- лось на 10\%, в России - на 2\%. Основным источником информации для респондентов всех возрастных категорий в России в 2019 г. стали новостные, аналитические и официальные сайты. На втором месте для граждан большинства возрастных категорий по-прежнему остается телевидение, однако как ключевой источник новостей оно в 2019 г. потеряло в среднем 9\%, за год на 7\% выросла значимость социальных сетей и блогов (для 37\% россиян).

Согласно Mediascope, на лето 2019 г. самой популярной у россиян ежедневной газетой были «Известия» (суммарная аудитория печатного издания и его сайта), телеканалом - «Россия 1» (по доле телезрителей), радио - «Европа плюс»1.

По данным ежегодного отчета о потреблении новостей Reuters Institute Digital News Report 2019 (в его основе опрос аудитории, проведенный в 38 странах), 32\% респондентов стараются избегать новостей ${ }^{3}$. Показатель увеличился по сравнению с тем, что было два года назад, когда Reuters в последний раз проводил опрос на эту тему. От сомнений читателей в качестве информации отчасти выигрывают известными новостные бренды. В четверти стран мира (26\%) люди говорят, что стали полагаться на более «авторитетные» источники новостей, а в США этот показатель вырос до 40\%.

Несмотря на то что особенности медиапотребления аудитории как в России, так и в мире достаточно хорошо исследованы, чаще всего они изучаются исходя из таких общих социально-демографических характеристик, как возраст, пол, место жительства, образование, уровень дохода и т.п. Например, исследовались особенности медиапотребления различных категорий СМИ молодежью (Кульчицкая, Вартанов, Дунас, Салихова и др., 2019; Дунас, Толоконникова, Черевко, 2018; Banaji, Buckingham, 2013; Bennett, Maton, Kervin, 2008), а также жителями различных регионов (Zubarevich, 2010). 
Однако на данный момент известных исследований медиапотребления представителей делового сообщества в России нет. Такое исследование представляется важным из-за того, что СМИ предположительно могут быть одним из факторов принятия бизнес-решений, а их потребление может являться частью рабочего процесса представителей бизнеса. Таким образом, объектом исследования в данной статье стали практики потребления СМИ представителями российского делового сообщества, представленного в исследовании финансовым сектором. Предмет исследования - характеристики подобных практик. Среди характеристик, выделенных нами: выбор тех или иных СМИ, частота и способы обращения к ним. Цель исследования - выявление наиболее общих закономерностей медиапотребления представителей российского бизнеса, касающихся выбора, частоты и способов потребления СМИ. Кроме того, мы хотели по возможности объяснить причины тех или иных закономерностей.

Исследование выполнено в контексте изучения принятия решений представителями отечественного делового сообщества на основе СМИ. Определение закономерностей медиапотребления этой группы первый шаг для изучения особенностей принятия решений на материалах медиа.

\section{Методика исследования}

В рамках исследования мы провели опрос методом анкетирования. Было отобрано 110 респондентов, работающих в финансовой сфере: розничных и инвестиционных банках, управляющих и брокерских компаниях, негосударственных пенсионных фондах (НПФ). Выбор именно финансовой сферы объясняется необходимостью сузить и стандартизировать выборку, чтобы получить более однородные ответы. Кроме того, финансовая сфера в России довольно развита: на момент написания статьи (но- ябрь 2019 г.) действовало более 400 банковских лицензий, 300 брокерских, более 200 доверительных управляющих, около 50 НПФ (данные Центробанка). Безусловно, одна финансовая организация может иметь сразу несколько лицензий (например, банка и брокера), однако в целом мы можем говорить о развитости и разнообразии финансового рынка России. Это значит, что на нем занято значительное количество специалистов разного уровня, которых мы могли бы привлечь для опроса в качестве респондентов.

В отличие от большинства секторов российской экономики в финансовом секторе заметна доля частных компаний по сравнению с государственными. Таким образом, мы получили информацию от людей, занятых как в частном, так и в государственном секторе экономики России. Еще одна причина выбора именно сотрудников финансовых организаций в качестве респондентов заключается в относительно легком доступе автора статьи к таким людям и возможности получить от них менее формальные и более откровенные ответы на свои вопросы (в течение нескольких лет автор статьи работала финансовым корреспондентом в различных российских СМИ). Благодаря этому удалось получить ответы как от сотрудников среднего звена, так и от топ-менеджеров крупнейших банков и других финансовых организаций.

Опрос проходил в июле-августе 2019 г. среди представителей московского финансового сектора. Он был проведен с использованием стандартного вопросника, рассылаемого по электронной почте. В опросе приняли участие следующие категории сотрудников финансовых компаний и банков: 20 топ-менеджеров (владельцы, генеральные директора, члены правления и совета директоров), 40 руководителей департаментов, 25 рядовых аналитиков и экономистов, 25 рядовых управляющих активами и трейдеров. Деление на груп- 
пы позволило отобразить многообразие функций и должностей сотрудников финансового сектора. В результате мы получили сведения как о высшем руководстве, так и о руководителях подразделений, а также о тех, кто непосредственно взаимодействует с клиентами (в первую очередь управляющие активами). Отметим также, что около половины респондентов работают в банковской сфере, остальные - в инвестиционной (управляющие компании, брокеры, НПФ, инвестиционные блоки банков).

Мы связались примерно со 150 потенциальными респондентами, получили ответы от 110 человек. По данным Росстата за второй квартал 2019 г., всего в финансовой и страховой деятельности занят 1,6 млн человек. Выборка представляется достаточно репрезентативной для целей исследования, погрешность можно оценить в 10\%, доверительную вероятность - в 97\%.

В анкете, которую получили респонденты, было 24 вопроса. Из них восемь - закрытые или полузакрытые (предусматривающие ответ «другое» с возможностью написать свой вариант), остальные - открытые. Вопросы касались как характеристик медиапотребления представителей отечественного делового сообщества, так и принятия ими профессиональных решений на основе СМИ. Поскольку статья является первой частью исследования особенностей принятия решений представителями российского бизнеса и в ней идет речь только о том, какие СМИ и как потребляют отечественные бизнесмены, в ней будут представлены результаты анализа ответов на вопросы только первого блока анкеты об особенностях медиапотребления. В нем преимущественно были закрытые и полузакрытые вопросы, а из открытых - только те, в которых требовалось перечислить конкретные СМИ, а также обозначить способ и время взаимодействия со СМИ. Мы предложили отдельно перечислить предпочитаемые прессу, телеканалы и радио- станции. В анкете были отдельные вопросы по деловым и неделовым СМИ. В итоге вопросы анкеты в части медиапотребления СМИ бизнесменами затронули следующие темы:

- чтение, слушание и просмотр деловых СМИ;

- чтение, слушание и смотрение неделовых СМИ;

- частота потребления СМИ (деловых и неделовых);

- способ и время потребления СМИ (деловых и неделовых).

Следует отметить, что о предпочитаемых СМИ мы спрашивали респондентов в контексте принятия решений, поэтому просили сфокусироваться на СМИ полезных для работы (не ограничивая, однако, респондентов только деловыми изданиями). Соответственно, практики потребления СМИ исключительно для развлечения нами не изучались.

Под «деловым сообществом» и «бизнесом» мы понимаем не только обладателей собственного дела, но и наемных сотрудников, которых среди респондентов большинство (92\%). Однако рядовых менеджеров (например, операционистов в банковских отделениях, сотрудников среднего звена в отделах и т.п.) мы не опрашивали, поскольку самостоятельно профессиональных решений они практически не принимают. В фокусе этой статьи - руководители компаний и департаментов, а также люди, занятые в индустрии управления, т.е. непосредственно оказывающие влияние на свои компании и клиентов. Руководители пресс-служб и отделов маркетинга не опрашивались, поскольку их работа непосредственно связана с присутствием их компаний в публичном поле.

\section{Характеристики потребления деловых медиа по типам СМИ}

Исходя из результатов опроса, мы можем констатировать: предпочтения пред- 
ставители российского делового сообщества отдают одним и тем же изданиям. Список таких СМИ невелик. Практически все ожидаемо называют один и тот же обязательный набор из трех основных деловых газет России - «Ведомости», «Коммерсанть" и «РБК».

Если говорить о журнальной прессе, то интерес к ней у делового сообщества слабый. Больше внимания респонденты уделяют к отраслевым финансовым изданиям. И в этом случае респонденты выбирали в основном одни и те же издания. Особенно часто к отраслевым СМИ обращаются руководители отделов и управляющие активами, что можно объяснить необходимостью глубже погружаться в повестку: именно эти две категории заняты непосредственной работой с клиентами. Поэтому помимо общеэкономическихтенденций руководителям и управляющим важно ориентироваться и в более узких темах, на которые чаще всего обращают внимание отраслевые медиа.

Представители отечественного делового сообщества, как показало анкетирование, преимущественно предпочитают прессу, радио слушает 28,5\% респондентов, телевидение смотрит - 23,6\%. В числе возможных причин такой особенности - небольшой выбор деловых радиостанций и телеканалов в России. При этом несколько большая популярность радио по сравнению с телевидением объясняется, скорее всего, возможностью слушать его в автомобиле, телевидение, к тому же, требует, как правило, большей вовлеченности. Если говорить о деловом радио и телевидении, то здесь также большого разнообразия в перечне СМИ нет.

Внимание представителей отечественного делового сообщества также привлекают иностранные СМИ, причем некоторые из них довольно популярны. В то же время иностранные деловые СМИ читает немногим более половины респондентов, что может свидетельствовать или о нежелании российского бизнеса погружаться в общемировой деловой контекст, или о языковом барьере. В целом российское деловое сообщество замкнуто именно на деловой повестке при выборе СМИ для чтения по работе - только одна пятая часть опрошенных бизнесменов обращается к неделовым медиа.

Ряд управляющих и трейдеров отметили, что помимо традиционных СМИ их интересуют профессиональные блоги, форумы и порталы - Zero Hedge, «Смартлаб», «БКС Экспресс». При этом никто из респондентов не отметил среди СМИ российские информационные агентства (например, «Интерфакс», ТАСС, МИА «Россия сегодня»). Возможно, это связано с тем, что конкретный бренд информагентства не слишком важен отечественным бизнесменам.

В таблице 1 представлен список самых популярных СМИ у представителей российского бизнеса, в таблице 2 - результаты опроса по предпочитаемым деловым отечественным СМИ, в таблице 3 - по предпочитаемым деловым зарубежным СМИ (отметим, что в этой категории самыми популярными стали информационные агентства, новости которых можно читать из одноименных терминалов для торговли ценными бумагами, что упрощает доступ к ним).

Что касается потребления для работы неделовых СМИ, то в этом вопросе среди представителей бизнеса единодушия не наблюдается. Ни один из опрошенных топменеджеров не привел примера предпочитаемого неделового СМИ. Выявить однозначных тенденций в предпочтениях по конкретным изданиям, радио и телеканалам среди остальных групп не представляется возможным: большинство респондентов затруднились назвать предпочитаемые неделовые СМИ. Всего около 20\% респондентов назвали конкретные медиа. 
Таблица 1. Самые популярные СМИ у представителей отечественного делового сообщества

\begin{tabular}{|l|c|}
\hline \multicolumn{1}{|c|}{ сми } & $\begin{array}{c}\text { Доля респондентов } \\
\text { от общего числа, \% }\end{array}$ \\
\hline Ведомости & 99,1 \\
\hline Коммерсанть & 87,3 \\
\hline РБК (кроме ТВ) & 68,2 \\
\hline Bloomberg & 38,2 \\
\hline Банки.ру & 28,2 \\
\hline РБК ТВ & 23,6 \\
\hline Бизнес.фм & 20,9 \\
\hline Reuters & 14,5 \\
\hline Financial Тітеs & 11,8 \\
\hline Коммерсанть.фм & 11,8 \\
\hline
\end{tabular}

Источник: данные опроса, расчеты автора статьи.

Таблица 2. Доля респондентов, читающих те или иные деловые отечественные СМИ, в \%

\begin{tabular}{|l|c|c|c|c|c|c|c|}
\hline \multicolumn{1}{|c|}{ Респонденты } & Ведомости & Коммерсанть & РБК & $\begin{array}{c}\text { Банки. } \\
\text { ру }\end{array}$ & Forbes & $\begin{array}{c}\text { Банковское } \\
\text { обозрение }\end{array}$ & $\begin{array}{c}\text { Investing. } \\
\text { com }\end{array}$ \\
\hline Топ-менеджеры & 100,0 & 90,0 & 35,0 & 25,0 & 5,0 & 0,0 & 0,0 \\
\hline Руководители & 100,0 & 87,5 & 67,5 & 47,5 & 7,5 & 10,0 & 0,0 \\
\hline Аналитики & 96,0 & 88,0 & 76,0 & 28,0 & 8,0 & 0,0 & 4,0 \\
\hline $\begin{array}{l}\text { Управляющие } \\
\text { и трейдеры }\end{array}$ & 100,0 & 84,0 & 88,0 & 0,0 & 0,0 & 0,0 & 8,0 \\
\hline Все & 99,1 & 87,3 & 68,2 & 28,2 & 5,5 & 3,6 & 2,7 \\
\hline
\end{tabular}

Источник: данные опроса, расчеты автора статьи.

Таблица 3. Доля респондентов, читающих те или иные деловые зарубежные СМИ, в \%

\begin{tabular}{|l|c|c|c|c|c|}
\hline \multicolumn{1}{|c|}{ Респонденты } & Bloomberg & Reuters & FT & WSJ & $\begin{array}{c}\text { The } \\
\text { Economist }\end{array}$ \\
\hline Топ-менеджеры & 20,0 & 0,0 & 5,0 & 0,0 & 0,0 \\
\hline Руководители & 27,5 & 7,5 & 5,0 & 2,5 & 2,5 \\
\hline Аналитики & 48,0 & 28,0 & 20,0 & 12,0 & 8,0 \\
\hline $\begin{array}{l}\text { Управляющие } \\
\text { и трейдеры }\end{array}$ & 60,0 & 24,0 & 20,0 & 16,0 & 0,0 \\
\hline Все & 38,2 & 14,5 & 11,8 & 7,3 & 2,7 \\
\hline
\end{tabular}

Источник: данные опроса, расчеты автора статьи. 
Таблица 4. Доля респондентов, предпочитающих отечественные и зарубежные СМИ, в \%

\begin{tabular}{|l|c|c|c|c|}
\hline \multicolumn{1}{|c|}{ Респонденты } & $\begin{array}{c}\text { Деловые } \\
\text { отечественные }\end{array}$ & $\begin{array}{c}\text { Деловые } \\
\text { зарубежные }\end{array}$ & $\begin{array}{c}\text { Неделовые } \\
\text { отечественные }\end{array}$ & $\begin{array}{c}\text { Неделовые } \\
\text { зарубежные }\end{array}$ \\
\hline Топ-менеджеры & 100,0 & 20,0 & 0,0 & 0,0 \\
\hline Руководители & 100,0 & 45,0 & 17,5 & 0,0 \\
\hline Аналитики & 100,0 & 80,0 & 32,0 & 8,0 \\
\hline $\begin{array}{l}\text { Управляющие } \\
\text { и трейдеры }\end{array}$ & 100,0 & 72,0 & 32,0 & 0,0 \\
\hline Все & 100,0 & 54,5 & 20,9 & 1,8 \\
\hline
\end{tabular}

Источник: данные опроса, расчеты автора статьи.

Таблица 5. Частота потребления деловых СМИ респондентами, в \%

\begin{tabular}{|l|c|c|c|c|c|c|}
\hline \multicolumn{1}{|c|}{ Респонденты } & $\begin{array}{c}\text { Практически } \\
\text { постянно/ } \\
\text { СМи всегда } \\
\text { фоном }\end{array}$ & $\begin{array}{c}\text { Несколько } \\
\text { раз в день }\end{array}$ & $\begin{array}{c}\text { Раз } \\
\text { в день }\end{array}$ & $\begin{array}{c}\text { Раз } \\
\text { в несколько } \\
\text { дней }\end{array}$ & $\begin{array}{c}\text { Несколько } \\
\text { раз } \\
\text { в неделю }\end{array}$ & Реже \\
\hline Топ-менеджеры & 0,0 & 25,0 & 65,0 & 10,0 & 0,0 & 0,0 \\
\hline Руководители & 32,5 & 52,5 & 12,5 & 2,5 & 0,0 & 0,0 \\
\hline Аналитики & 60,0 & 40,0 & 0,0 & 0,0 & 0,0 & 0,0 \\
\hline $\begin{array}{l}\text { Управляющие } \\
\text { и трейдеры }\end{array}$ & 44,0 & 48,0 & 8,0 & 0,0 & 0,0 & 0,0 \\
\hline Все & 35,5 & 43,6 & 18,2 & 2,7 & 0,0 & 0,0 \\
\hline
\end{tabular}

Источник: данные опроса, расчеты автора статьи.

Таблица 6. Частота потребления неделовых СМИ респондентами, в \%

\begin{tabular}{|l|c|c|c|c|c|c|}
\hline \multicolumn{1}{|c|}{ Респонденты } & $\begin{array}{c}\text { Практически } \\
\text { постоянно/ } \\
\text { сми всегда } \\
\text { фоном }\end{array}$ & $\begin{array}{c}\text { Несколько } \\
\text { раз в день }\end{array}$ & $\begin{array}{c}\text { Раз в } \\
\text { день }\end{array}$ & $\begin{array}{c}\text { Раз в } \\
\text { несколько } \\
\text { дней }\end{array}$ & $\begin{array}{c}\text { Несколько } \\
\text { раз } \\
\text { в неделю }\end{array}$ & Реже \\
\hline Топ-менеджеры & 0,0 & 10,0 & 15,0 & 10,0 & 30,0 & 35,0 \\
\hline Руководители & 0,0 & 15,0 & 60,0 & 12,5 & 5,0 & 7,5 \\
\hline Аналитики & 8,0 & 36,0 & 40,0 & 16,0 & 0,0 & 0,0 \\
\hline $\begin{array}{l}\text { Управляющие } \\
\text { и трейдеры }\end{array}$ & 12,0 & 16,0 & 60,0 & 0,0 & 12,0 & 0,0 \\
\hline Все & 4,5 & 19,1 & 47,3 & 10,0 & 10,0 & 9,1 \\
\hline
\end{tabular}

Источник: данные опроса, расчеты автора статьи. 
По двое опрошенных отметили, что обращаются к BBC, «Российской газете», «Известиям» и Meduza, по одному - «Новой газете», The Washington Post, The New York Times, CNN, Euronews, FOX News. Несмотря на небольшое количество примеров, можно отметить, что иностранные неделовые СМИ в российской бизнес-среде довольно распространены (см. табл. 4).

\section{Другие характеристики медиапотребления}

Треть респондентов признались, что читают деловые СМИ практически постоянно или они всегда идут фоном (см. табл. 5). Данные по неделовым СМИ представлены в таблице 6.

Также мы попросили респондентов по возможности отметить, каким образом они чаще всего получают новостные сообщения из СМИ. Выяснилось, что $87 \%$ топ-менеджеров получают новости преимущественно из корпоративных рассылок, которые делают представители пресс-служб. Как правило, это новостные дайджесты, которые касаются отрасли и самой компании. Чаще всего рассылки ежедневные. Таким образом, это сильно сужает повестку для руководителей. Правда, 60\% из них также отметили, что иногда и сами просматривают избранные СМИ.

Опрошенные руководители департаментов в основном читают СМИ самостоятельно, при этом часто стараются это делать раз в день. Ряд руководителей упомянул, что сайты новостных СМИ в Интернете, которые специализируются в том числе на финансовой тематике, у них открыты всегда. Некоторые руководители отметили, что постоянно отслеживают форумы банковских клиентов (например, сайты «Банки.ру» и «Сравни.ру»), что помогает им улучшать сервис и предложение для собственных клиентов.

Аналитики и управляющие в целом наиболее активно из всех респондентов ипользуют СМИ для работы, что во многом объясняется спецификой их деятельности: от полученных новостей часто зависят аналитические прогнозы и решения по покупке и продаже ценных бумаг. Все они отметили, что получают информацию самостоятельно, часто отслеживая новости «на фоне». Около четверти респондентов этих двух категорий указали, что важную роль для получения информации для них играют терминалы Bloomberg и Reuters, где помимо возможности торговать бумагами и отслеживать котировки есть новостная лента, которая обновляется в режиме онлайн.

Если говорить о времени потребления новостей, то 68\% всех респондентов (100\% топ-менеджеров) отметили, что пик приходится на начало рабочего дня. Это довольно консервативный стиль потребления: как уже было отмечено выше, исследователи уже много лет говорят о том, что с появлением Интернета график посещаемости сайтов СМИ значительно сгладился - традиционные ранее пики посещаемости (утро, обеденный перерыв, вечер) теперь не так очевидны, поскольку уже у очень многих есть мобильный телефон с выходом в Интернет и почти все работают за компьютерами с доступом в Сеть.

\section{Заключение}

Результаты опроса свидетельствуют о том, что в целом в деловой среде в России принято читать деловые СМИ регулярно: за редким исключением минимум раз в день или чаще. В то же время регулярность взаимодействия со СМИ зависит от того, к какой группе принадлежит респондент. Наименее активны топ-менеджеры: даже деловые СМИ никто из них не потребляет постоянно, а почти две трети из них и вовсе обращаются к медиа раз в день. Руководители отделов куда более включены в процесс потребления СМИ: почти треть из них постоянно или фоном. Как следует из результатов анкетирования, наиболее 
активной категорией в плане потребления СМИ являются аналитики, несколько отстают от них управляющие. Действительно, именно для аналитика при составлении рекомендаций и обзоров важно ориентироваться в новостной повестке, от которой во многом зависит конъюнктура рынка. Кроме того, довольно часто аналитики выпускают прогнозы, которые строятся на сообщениях из СМИ: например, когда журналисты первыми узнают о планах Минфина по размеру дивидендов Сбербанка на ближайшие годы или эксклюзивную информацию о желании «Газпрома» изменить инвестпрограмму. Именно эти представители российского делового сообщества наиболее часто обращаются к СМИ в процессе работы.

Похожая ситуация и с неделовыми СМИ, которые на постоянной основе потребляют для работы только редкие аналитики и управляющие. Вероятно, это связано с необходимостью более подробно отслеживать также социальную и политическую повестку в СМИ, поскольку политика непосредственно влияет на экономические решения государств и граждан. Хотя в целом и к неделовым СМИ интерес достаточно высок: почти половина респондентов обращается к ним раз в день, еще четверть - чаще. Исключение - топ-менеджеры, две трети которых потребляют неделовые СМИ в рабочих целях несколько раз в неделю и реже.

Если делать общий вывод о частоте потребления СМИ (как деловых, так и неделовых) представителями отечественного делового сообщества, то в случае деловых СМИ наиболее характерно их потребление несколько раз в день, для неделовых раз в день. В читательских предпочтениях отечественные бизнесмены единодушны: они предпочитают деловую отечествен ную прессу. Все респонденты отмечали, что читают «Ведомости», «Коммерсанть» или «РБК», либо все три газеты. Самым популярным изданием в российском деловом сообществе, исходя из результатов опроса, является газета «Ведомости». С одной стороны, это, безусловно, свидетельствует об интересе к российским деловым изданиям, с другой - об отсутствии большего выбора изданий такого рода на отечественном медиарынке. Таким образом, большинство представителей российского делового сообщества знакомы с одной и той же повесткой дня в одних и тех же СМИ.

\section{Примечания}

${ }^{1}$ Медиапотребление в России - 2019 / Deloitte. Режим доступа: http://www2.deloitte. com

2 Данные по аудитории СМИ / Mediascope. Режим доступа: https://mediascope.net/ data/

3 Digital News Report 2019. Reuters Institute. Режим доступа: http://www.digitalnewsreport.org

\section{Библиография}

Амзин А.А. Особенности медиапотребления // Как новые медиа изменили журналистику / под науч. ред. С.Д. Балмаевой и М.М. Лукиной. Екатеринбург: Гуманит. ун-т, 2016. С. 86-100.

Дунас Д.В., Толоконникова А.В., Черевко Т.С. Наблюдение за потреблением информационного контента студентами факультета журналистики МГУ // Медиаскоп. 2018. Вып. 4. Режим доступа: http://www.mediascope.ru/2483 DOI: 10.30547/mediascope.4.2018.1 
Кульчицкая Д.Ю., Вартанов С.А., Дунас Д.В., Салихова Е.А. и др. Медиапотребление молодежи: специфика методологии исследования // Медиаскоп. 2019. Вып. 1. Режим доступа: http://www.mediascope.ru/2529 DOI: 10.30547/mediascope.1.2019.9

Лосева Н.Г. Аудитория новых медиа // Как новые медиа изменили журналистику / под науч. ред. С.Д. Балмаевой и М.М. Лукиной. Екатеринбург: Гуманит. ун-т, 2016. С. 31-85.

Мультимедийная журналистика / под общ. ред. А.Г. Качкаевой, С.А. Шомовой. М.: ИД ВШЭ, 2017.

Полуэхтова И.А. Социология массовых коммуникаций: курс лекций: в 2 ч. Ч. 1. М.: Изд-во Моск. гуманит. ун-та, 2012.

Черных А.И. Социология массовых коммуникаций. М.: ИД ВШЭ, 2008.

Banaji S., Buckingham D. (2013) The Civic Web: Young People, the Internet, and Civic Participation. Cambridge: MIT Press.

Bennett S., Maton K., Kervin L. (2008) The 'Digital Natives' Debate: A Critical Review of the Evidence. British Journal of Educational Technology 39: 32-45.

Boczkowski P., Mitchelstein E. (2010) Is There a Gap between the News Choices of Journalists and Consumers? A Relational and Dynamic Approach. International Journal of Press/Politics 15: 19-29.

Fishman M. (1980) Manufacturing the News: The Social Organization of Media News Production. Austin: University of Texas Press.

Gans H. (2004) Democracy and the News. Oxford: Oxford University Press.

Harsh T., Webster J., Malthouse E., Ksaizek T. (2012) Media Consumption Across Platforms: Identifying User-Defined Repertoires. New Media and Society 14: 105-119.

Kormelink G., Meijer I. (2018) What Clicks Actually Mean: Exploring Digital News User Practices. Journalism 19 (5): 21-38. DOI: 10.1177/1464884916688290

MacGregor P. (2007) Tracking The Online Audience. Journalism Studies 8: 7-16.

Meijer C., Kormelink G. (2014) Checking, Sharing, Clicking and Linking: Changing patterns of news use between 2004 and 2014. Digital Journalism 1: 1-16.

Nelson J., Webster J. (2017) The Myth of Partisan Selective Exposure: A Portrait of the Online Political News Audience. Social Media + Society 3 (3): 89-106. DOI: 10.1177/2056305117729314

Verhoeven M., von Rimscha B., Krebs I., Siegert G. et al. (2017) Identifying Paths to Audience Success of Media Products: the Media Decision-Makers' Perspective. International Journal on Media Management 2: 1-27. DOI: 10.1080/14241277.2017.1402019

Zubarevich N. (2010) State-Business Relations in Russia's Regions. In: Gelman V.Y., Ross C. (eds.) The Politics of Sub-National Authoritarianism in Russia. London: Ashgate, pp. 211-227. 